\title{
Farklı Kültürlerdeki Rezerve Boya/Baskı Teknikleri Üzerine Kavram ve Terimler
}

Elif KURTULDU*, Leyla YILDIRIM**

Kurtuldu, E. ve Yıldırım, L. (2019). Farklı kültürlerdeki rezerve boya/baskı teknikleri üzerine kavram ve terimler. YEDİ: Sanat, Tasarım ve Bilim Dergisi. Kış 2019 (21), s. 93-103.

Araştırma Makale / Research Article

Özet

Tekstil sanatının plastik sanatlarla olan etkileşimi 1960’lı yıllardan itibaren lif sanatı kapsamında yeni açılımları gündeme getirmiştir. Bu yeni yaklaşımlar malzemeden forma, yeni teknolojilerden geleneksel tekniklere kadar geniş bir perspektifi içinde barındırmaktadır. Bu çalışmalar kapsamında rezerve boyama teknikleri ise gittikçe popülerlik kazanmış ve değişik yorumlarla tekstil sanatının gelişimine önemli katkılar sağlamıştır. Ancak bu tekniklerin çok eski dönemlerden itibaren geniş bir coğrafyada uygulanması ve kültürel etkileşimlerin olması nedenleriyle farklı terim ve kavramların ortaya çıkışı gündeme gelmiştir.

Bu çalışmada rezerve teknikleri fiziksel, mekanik ve kimyasal olmak üzere üç ana başlık altında toplanarak, coğrafi bölgeler (Uzak Doğu ve Asya, Afrika, Avrupa, Amerika), rezerve uygulama aşamaları (iplik, kumaş, ürün), boya uygulama teknikleri (fırça, daldırma), kullanılan kumaş türleri, rezerve malzemeleri (iplik, boncuk, boru, şablon, mum, kil vb.) kullanılan araçlar (Tijanting, klamp vb) dikkate alınarak bir sınıflandırma yapılmaya çalışılmış ve bir kavramlar bütünü oluşturulması amaçlanmıştır.

Anahtar Sözcükler: Tekstil sanatı, Boyama teknikleri, Rezerve boyama, Rezerve baskı, Terimler

\section{Concepts And Terms The Techniques Dyeing And Printing On Different Cultures}

\section{Abstract}

The interaction of textile art with plastic arts has brought new expansions to the agenda since the 1960s. These new approaches cover a broad perspective from materials to form and from new technologies to traditional techniques. Within the scope of these studies, resist dyeing techniques have gained popularity and have made important contributions to the development of textile art with different interpretations. However, due to the application of these techniques in a wide geography and cultural interactions since ancient times, different terms and concepts have emerged.

In this study, resist dye techniques were collected under three main headings as physical, mechanical and chemical categories. And it was aimed to create a whole set of concepts considering to geographic regions (Far East and Asia, Africa, Europe, America), resist application stages (yarn, fabric, product), paint application techniques (brush, immerse), types of fabrics used, reserve materials (thread, bead, pipe, stencil, wax, clay, etc.) the tools used (tijanting, clamp, etc.)

Keywords: Textile art, Dyeing techniques, Resist dyeing, Resist printing, Terms 


\section{Giriş}

Uygarlığın ilk dönemlerinden itibaren insanlığın içinde, bulunduğu çevreyi farklı amaçlar ile süsleme isteği olmuştur (Wells, 1997, s. 8). Tarih boyunca uygarlıklar yaşadıkları coğrafyanın, inançlarının, iklim şartlarının ve mevcut teknolojilerinin doğrultusunda, liften bitmiş ürüne kadar her aşamada tekstil malzemelerini estetik ve işlevsel amaçlarla renklendirmişlerdir. Ticaret, göç, savaşlar gibi pek çok sebeple iletişim halinde olan, birlikte yaşayan toplumlar her alanda olduğu gibi tekstil tasarım ve üretiminde bilgi alışverişi yapmışlar ve birbirlerini etkilemişlerdir. Tekstildeki renklendirme işlemleri inanç, statü, cinsiyet gibi sebepler ile her toplumda farklı uygulamalar şeklinde gelişmiştir. Bu süreçte bazı toplumlardaki teknikler yeniliğe açık bir şekilde gelişirken bazı toplumlarda geleneksel teknikler yüzyıllar boyunca aynı kalmıştır. Bu gelişim sürecinde ticari bir olgu olarak modada daima etkili olmuştur.

Tekstilde renklendirme işlemleri boyama ve baskı olmak üzere iki ayrı teknik ile yapılmaktadır (Wells, 1997, s. 8). Farklı kültürlerde, ilkel üretimlerden günümüze kadar gelen süreçte pek çok farklı teknikte boya ve baskı tekniklerinin kullanıldığı bilinmektedir. Bu tekniklerden biri de rezerve (resist) tekniğidir. Rezerve tekniğinde rezerve malzemesinin uygulandığı yerler zemin renginde kalmakta, rezerve edilmemiş alanlar ise uygulanan boyarmaddenin rengini alarak deseni oluşturmaktadır (Thompson, 2014, s. 248).

Tekstil malzemelerinin doğal renklendiricilerle veya boyalarla elle süslenmesi, en ilkel kabileler tarafından bilinmekteydi. Nişasta macunu veya sıcak mumun yanı sıra düğümleme, katlama ve bağlama gibi rezerve teknikleri tarihin kayıtlanan ilk zamanlarında da biliniyordu (Belfer, 1992, s. XI). İlk rezerve boya-baskının ne zaman yapıldığı bilinmemekle beraber, M.Ö. 200-100 yıllarında Peru ve M.S. 700-1500 yıllarında Kolomb-öncesi medeniyetlerin ilk rezerve örnekleri sergilediği ifade edilmektedir (Wells, 1997, s. 10). Uzak Doğu, Japonya, Çin, Endonezya, Hindistan, Malezya, Mısır, İran, Kafkasya, Rusya gibi ülkelerde geleneksel boyabaskı tekniklerinin kullanımı oldukça yaygındır.

Rezerve boyamanın başladığı yer olarak düşünülen Hindistan'da, boyaların ve mordanların reçetelerinde yer alan karmaşık teknoloji benzersiz derecede mükemmellik derecesine hâkimdi (Belfer, 1992, s. 2). Ancak daha da eskiye gidildiğinde Han Hanedanlığı, T'ang Hanedanlığı, Nara Dönemi, Persler ve Eski Yunan'da da rezerve boya-baskının var olduğu düşünülmektedir. Mısır kazılarında ortaya çıkan 4. yüzyıla ait örnekler de rezerve tekniği ile üretilmiştir. Çin'in Jiangxi bölgesindeki mağaralarda gerçekleştirilen kazılarda bulunan kumaşların iki tahta rakle arasına sıkıştırılarak (jiaxie tekniği) rezerve edilip boyandığı düşünülmektedir. Yine Heian Dönemi'nde Japonya'da kyokechi tekniği ile boyanmış kumaş, rezerve boya baskı tekniklerinin varlığını kanıtlamakla beraber, kültürlerin birbirleri ile etkileşim içerisinde olduğunu da yansıtmaktadır (Erdem İşmal ve Yıldırım, 2012, s. 18-22).

M.S. 2. yüzyılda Arap tüccarlar Kızıldeniz üzerinden Avrupa'ya Hint kumaşları götürerek Hintlilerin baskılı kumaşlarının dünya çapında yayılmasını sağlamış ve zamanla da Batı Afrika'ya kadar ticaret yolları genişlemiştir (Wells, 1997, s. 9). Özellikle Japonya ve Çin'de bu dönemde rezerve boya baskı teknikleri büyük ölçüde kullanılmıştır.

Hindistan'daki tekstil malzemelerinin rezerve edilip renklendirilmesinde iki yöntem kullanılmaktadır. Birincisi bağlama ve boyama, ikincisi ise boya-baskı işlemleridir (Gillow ve Barnard, 1993, s. 38). Rezerve tekniği ile farklı boyama metotlarının Pre-Columbian toplumunda M.S. 7001500 yıllarında geliştiği bilinmektedir (Wells, 1997, s. 10).

Rezerve tekniği, "kumaşta boya alması istenmeyen yerlerin kimyasal maddeler veya mekanik olarak, mum, kil, bağlama, dikiş, sıkıştırma, katlama, büzme, düğüm vs. gibi farklı şekillerde kapatılarak yapılan boyama tekniğidir" (Erdem İşmal § Yıldırım, 2012, s. 154). Rezerve tekniği, farklı kültürlerde üretim yöntemlerine göre farklı isimler almıştır. Renk alması istenmeyen bölgeleri kapatılarak yapılan rezerve boyama, iplik, kumaş ve bitmiş ürün şeklinde tekstil üretiminin çeşitli aşamalarında uygulanabilmektedir. Kumaş üzerinde doğrudan boyama ile desenlendirme işlemine dair ilk yöntemler, desenin boyarmaddeye karşı fiziksel engel oluşturan bir madde ile kapatılmasına dayanmaktadır. Böylelikle kumaş boyandığında rezerve edilen alanlar boyanmamıştır. Rezerve boyama; nişasta, zamk, kil, mum gibi basit bir rezerve maddesi ile kapatma, dikme veya sıkıştırma, mordan ve kimyasal reçinelerin kullanımına kadar geniş bir uygulama alanından oluşmaktadır (Foulds, 1995, s. 5). 


\section{Rezerve Boya/Baskı Tekniğinin Sınıflandırılması}

Birbirine yakın kültürlerde benzer rezerve boya ve baskı teknikleri farklı isimlerle adlandırılmakta ve uygulamadaki rezerve şekline bağlı olarak bu isimlendirmeler gittikçe dallanmakta ve çeşitlenmektedir. Bu durum ise aynı tekniğin farklı adlandırılmasından dolayı farklı bir teknik gibi algılanmasına neden olmaktadır. Aynı tekniklerin farklı isimlendirilmelerinin bir diğer nedeni de bölgede yetişen lif türüne bağlı olarak kullanılan iplik veya kumaş farklılıklarıdır. İplik ve kumaşların çeşitliliği, kullanılan yardımcı malzemelerin de farklılaşmasına sebep olmuştur. Örneğin; rezerve işleminin bir malzeme yardımıyla gerçekleştirildiği tekstil malzemelerine bakıldığında, Japonya'da ipek kumaşın şablon (stencil) kullanılarak desenlendirildiği, Afrika'da pamuklu kumaşın el kalıbı yardımıyla Çin'de ise her iki tekniğin kullanıldığı bilinmektedir.

Rezerve tekniklerinin farklı şekillerde sınıflandırılması mümkündür. Örneğin Belfer, rezerve tekniklerini sıcak rezerveler, bağlama ve düğümleme rezerveler, dikiş ile rezerve, klamp rezerve olarak sınıflandırmaktadır (Belfer, 1992, s. 5-8). Thompson ise rezerve tekniklerini ikat (iplik bağlama), batik (sıcak rezerve) ve bağlama-boyama (kumaş rezerve) olarak üçe ayırmıştır (Thompson, 2014, s. 249). Bunun yanı sıra mekanik rezerve, bağlama boyama, sıkıştırma, dikme rezerve, kimyasal rezerve ve ikat teknikleri olarak yapılan sınıflandırmalar da görülmektedir (Teker: 2015).

Bu çalışmada rezerve teknikleri; fiziksel, mekanik ve kimyasal olmak üzere üç ana başlık altında; Amerika)

- Coğrafi bölgeler (Uzak Doğu ve Asya, Afrika, Avrupa,

- Rezerve uygulama aşamaları (iplik, kumaş, ürün)

- Boya uygulama teknikleri (fırça, daldırma)

- Kullanılan kumaş türleri kil vb.)

- Rezerve malzemesi (iplik, boncuk, boru, şablon, mum,

- Kullanılan araç ve gereçler (Tijanting, clamp vb) dikkate alınarak incelenmiş ve sınıflandırma yapılarak bir tablo oluşturulmaya çalışılmıştır (Tablo 1).
Tablo 1: Rezerve Tekniklerinin Uygulanmasında Kullanılan Malzeme Ve Araçlar

\begin{tabular}{|c|c|}
\hline Rezerve Maddeleri & $\begin{array}{l}\text { Balmumu } \\
\text { Mum } \\
\text { Pirinç unu } \\
\text { Misır unu } \\
\text { Gutta } \\
\text { Çamur }\end{array}$ \\
\hline Araç/Gereçler & $\begin{array}{l}\text { Özel metal kepçe (tjanting) } \\
\text { Metal kalıp (tjap), } \\
\text { Mengeneler } \\
\text { Fırçalar } \\
\text { Şablonlar } \\
\text { Ahşap parçaları } \\
\text { Plastik, akrilik şekiller } \\
\text { (üçgen, daire, kare vb.) } \\
\text { Çakıl taşları, pirinç taneleri, } \\
\text { boncuklar } \\
\text { Tahta mandallar } \\
\text { Lastik } \\
\text { İpler }\end{array}$ \\
\hline
\end{tabular}

Rezerve boyama teknik açıdan bakıldığında fiziksel, mekanik ve kimyasal olmak üzere üç şekilde gerçekleştirilmektedir (Wells, 1997, s. 125) (Tablo 2). Fiziksel rezerve boyamalar; bağlama, düğümleme, katlama, dikiş gibi malzemenin kendi imkânları ile mekanik ve kimyasal bir işleme gerek kalmadan iplik, kumaş veya ürünlerin bölgesel olarak renk gelişiminin engellenmesi ile gerçekleştirilmektedir. Mekanik rezerve boyamalarda ise; iplik, kumaş veya bitmiş ürünlerin bölgesel olarak renk gelişimlerinin engellenmesi, tahta, ip gibi yardımcı malzemeler tarafından kapatılması ile gerçekleşmektedir. Kimyasal rezerve boyamalarda ise iplik, kumaş veya bitmiş ürünler, bal mumu, nişasta, pirinç macunu, çamur, kil gibi malzemeler ile kapatılarak renk gelişimlerinin engellenmesi ile yapılmaktadır. 
Tablo 2: Kullanılan Teknik Açısından Rezerve Tekniklerinin Siniflandirilması

\begin{tabular}{|ll|}
\hline $\begin{array}{l}\text { Fiziksel rezerve boyama } \\
\text { (klampsız), dikiş }\end{array}$ & Bağlama (düğümleme), Katlama \\
\hline Mekanik rezerve boyama & Klamp, ip yardımı ile (sarma) \\
\hline $\begin{array}{l}\text { Kimyasal rezerve boyama } \\
\text { macunu, çamur ve kil ile }\end{array}$ & Bal mumu, nişasta, pirinç \\
\hline
\end{tabular}

Rezerve boyama, kullanılan teknik ve malzemeler açısından her coğrafi bölgede farklı isimler almaktadır. Bu çalışmada işlem aşaması açısından rezerve boyama; ipliklere, kumaşlara ve bitmiş ürünlere uygulanan rezerve işlemleri olarak üç gruba ayrılmıştır (Tablo 3). Coğrafi bölgelere göre ise bu malzemelere uygulanan rezerve işlemleri fiziksel, mekanik ve kimyasal rezerve işlemleri başlıkları ile detaylandırılmıştır.

Tablo 3: Rezerve Tekniklerinin Uygulandığı Aşamalara Göre Sinıflandirılması

\begin{tabular}{|lll|}
\hline $\begin{array}{l}\text { İplik rezerve } \\
\text { boyama }\end{array}$ & $\begin{array}{l}\text { Kumaş rezerve } \\
\text { boyama }\end{array}$ & $\begin{array}{l}\text { Ürün rezerve } \\
\text { boyama }\end{array}$ \\
\hline
\end{tabular}

Rezerve tekniklerine farklı bölgelerde verilen isimler aşağıdaki Tablo 4-11'de gösterilmiştir. Bu terimler kullanılan bölgeye özgü düzenlenmiştir ancak uygulanış açısından yöreye özgü bir teknik uygulanıp özel bir ad verilmedikçe tüm rezerve uygulamaları genel olarak bağlama/boyama (tie/dye), batik vb. yaygın olarak kullanılan isimlerle anılmaktadır. Burada yer alan terim ve kavramlar erişilebilen kaynaklar doğrultusunda olup yeni yapılan araştırmalarla genişletilebilme olanağına sahiptir.
Tablo 4: Özbekistan'da Rezerve Boyama Tekniklerine Verilen İsimler

\begin{tabular}{|l|l|l|l|}
\hline $\begin{array}{l}\text { Rezerve } \\
\text { Yöntemi }\end{array}$ & $\begin{array}{l}\text { Rezerve } \\
\text { Tekniği }\end{array}$ & $\begin{array}{l}\text { Uygulama } \\
\text { Alanı }\end{array}$ & $\begin{array}{l}\text { Tekniğe Verilen } \\
\text { Ad }\end{array}$ \\
\hline $\begin{array}{l}\text { Fiziksel } \\
\text { Yöntemler }\end{array}$ & Düğümleme & İplik & $\begin{array}{l}\text { Abr-bandi } \\
\text { Abra } \\
\text { Baghmal }\end{array}$ \\
\hline $\begin{array}{l}\text { Mekanik } \\
\text { Yöntemler }\end{array}$ & $\begin{array}{l}\text { İp yardımı ile } \\
\text { rezerve }\end{array}$ & Kumaş & $\begin{array}{l}\text { Shoi } \\
\text { Bakasab } \\
\text { Podshokhi }\end{array}$ \\
\hline
\end{tabular}

Tablo 5: Hindistan'da Rezerve Boyama Tekniklerine Verilen İsimler

\begin{tabular}{|c|c|c|c|}
\hline $\begin{array}{l}\text { Rezerve } \\
\text { Yöntemi }\end{array}$ & $\begin{array}{l}\text { Rezerve } \\
\text { Tekniği }\end{array}$ & $\begin{array}{l}\text { Uygulama } \\
\text { Alanı }\end{array}$ & $\begin{array}{l}\text { Tekniğe Verilen } \\
\text { Ad }\end{array}$ \\
\hline $\begin{array}{l}\text { Fiziksel } \\
\text { Yöntemler }\end{array}$ & Düğümleme & Kumaş, ürün & $\begin{array}{l}\text { Bandhani } \\
\text { Bandana } \\
\text { Banda } \\
\text { Odhani } \\
\text { Orni } \\
\text { Chunari } \\
\text { Leharia }\end{array}$ \\
\hline \multirow{2}{*}{$\begin{array}{l}\text { Mekanik } \\
\text { Yöntemler }\end{array}$} & $\begin{array}{l}\text { İp yardımı } \\
\text { ile rezerve }\end{array}$ & İplik & $\begin{array}{l}\text { İkat } \\
\text { Patola } \\
\text { Mashru } \\
\text { Mengikat } \\
\text { Chitka } \\
\text { Telia-rumal }\end{array}$ \\
\hline & $\begin{array}{l}\text { Ahşap, } \\
\text { şablon, } \\
\text { klamp } \\
\text { yardımı ile } \\
\text { rezerve }\end{array}$ & Kumaş & İtajime \\
\hline \multirow{3}{*}{$\begin{array}{l}\text { Kimyasal } \\
\text { Yöntemler }\end{array}$} & Çamur, kil & Kumaş, ürün & Tezekuri \\
\hline & \multirow{2}{*}{ Balmumu } & İplik & İkat \\
\hline & & Kumaş & Batik \\
\hline
\end{tabular}


Tablo 6: Japonya'da Rezerve Boyama Tekniklerine Verilen İsimler

\begin{tabular}{|c|c|c|c|}
\hline $\begin{array}{l}\text { Rezerve } \\
\text { Yöntemi }\end{array}$ & $\begin{array}{l}\text { Rezerve } \\
\text { Tekniği }\end{array}$ & $\begin{array}{l}\text { Uygulandı̆̆ } \\
\text { Yüzey }\end{array}$ & $\begin{array}{l}\text { Tekniğe Verilen } \\
\text { Ad }\end{array}$ \\
\hline \multirow{4}{*}{$\begin{array}{l}\text { Fiziksel } \\
\text { Yöntemler }\end{array}$} & Düğümleme & Kumaş, ürün & Shibori \\
\hline & \multirow[b]{2}{*}{$\begin{array}{l}\text { Katlama } \\
\text { (klampsız) }\end{array}$} & İplik & Arashi \\
\hline & & Kumaş & $\begin{array}{l}\text { Suji } \\
\text { Aizome } \\
\text { Kokechi }\end{array}$ \\
\hline & Dikiş & Kumaş & \\
\hline \multirow{3}{*}{$\begin{array}{l}\text { Mekanik } \\
\text { Yöntemler }\end{array}$} & \multirow[t]{2}{*}{$\begin{array}{l}\text { İp yardımı } \\
\text { ile rezerve }\end{array}$} & İplik & $\begin{array}{l}\text { Kasuri } \\
\text { Bing } \\
\text { E-gasuri } \\
\text { Ne-maki }\end{array}$ \\
\hline & & Kumaş & Laheria \\
\hline & $\begin{array}{l}\text { Ahşap, } \\
\text { şablon, } \\
\text { klamp } \\
\text { yardımı ile } \\
\text { rezerve }\end{array}$ & Kumaş & $\begin{array}{l}\text { Kyokechi } \\
\text { İtajime shibori } \\
\text { Beni ita } \\
\text { Beni itajime } \\
\text { Kyo beni } \\
\text { Tatsumaki } \\
\text { Yuzen }\end{array}$ \\
\hline \multirow[b]{3}{*}{$\begin{array}{l}\text { Kimyasal } \\
\text { Yöntemler }\end{array}$} & Balmumu & Kumaş & $\begin{array}{l}\text { Rokechi } \\
\text { Roketsuzome }\end{array}$ \\
\hline & \multirow[b]{2}{*}{$\begin{array}{l}\text { Nişasta, } \\
\text { pirinç } \\
\text { macunu } \\
\text { (Stencil } \\
\text { yardımı ile) }\end{array}$} & İplik & Hogushiori \\
\hline & & Kumaş & $\begin{array}{l}\text { Tsugugami } \\
\text { Tsutsugaki } \\
\text { Katazome } \\
\text { Bingatazome } \\
\text { Tsutsugakizome } \\
\text { Shiborizome } \\
\text { Tsujigana } \\
\text { Nazome }\end{array}$ \\
\hline
\end{tabular}

Tablo 7: Çin'de Rezerve Boyama Tekniklerine Verilen İsimler

\begin{tabular}{|c|c|c|c|}
\hline $\begin{array}{l}\text { Rezerve } \\
\text { Yöntemi }\end{array}$ & $\begin{array}{l}\text { Rezerve } \\
\text { Tekniği }\end{array}$ & $\begin{array}{l}\text { Uygulandığı } \\
\text { Yüzey }\end{array}$ & $\begin{array}{l}\text { Tekniğe } \\
\text { Verilen Ad }\end{array}$ \\
\hline \multirow{4}{*}{$\begin{array}{l}\text { Fiziksel } \\
\text { Yöntemler }\end{array}$} & \multirow[t]{2}{*}{ Düğümleme } & İplik & $\begin{array}{l}\text { Panban } \\
\text { Hainan } \\
\text { Qingpan } \\
\text { Valerian-dye }\end{array}$ \\
\hline & & Kumaş & $\begin{array}{l}\text { Hua Li } \\
\text { Zha-Jiao } \\
\text { Zha-Ran }\end{array}$ \\
\hline & $\begin{array}{l}\text { Katlama } \\
\text { (klampsız) }\end{array}$ & Kumaş & $\begin{array}{l}\text { Jia-xie } \\
\text { Zha ran }\end{array}$ \\
\hline & Dikiş & Kumaş & Feng Jiao \\
\hline $\begin{array}{l}\text { Mekanik } \\
\text { Yöntemler }\end{array}$ & $\begin{array}{l}\text { Ahşap, } \\
\text { şablon, klamp } \\
\text { yardımı ile } \\
\text { rezerve }\end{array}$ & Kumaş & $\begin{array}{l}\text { Jiao-xie, } \\
\text { Jia-xie }\end{array}$ \\
\hline \multirow{3}{*}{$\begin{array}{l}\text { Kimyasal } \\
\text { yöntemler }\end{array}$} & \multirow{3}{*}{ Balmumu } & İplik & $\begin{array}{l}\text { Huixie (kül } \\
\text { ile rezerve) }\end{array}$ \\
\hline & & Kumaş & $\begin{array}{l}\text { Huixie (kül } \\
\text { ile rezerve) }\end{array}$ \\
\hline & & Bitmiş ürün & $\begin{array}{l}\text { Huixie (kül } \\
\text { ile rezerve) }\end{array}$ \\
\hline
\end{tabular}

Tablo 8: Afrika'da Rezerve Boyama Tekniklerine Verilen İsimler

\begin{tabular}{|l|l|l|l|}
\hline $\begin{array}{l}\text { Rezerve } \\
\text { Yöntemi }\end{array}$ & Rezerve Tekniği & $\begin{array}{l}\text { Uygulandığı } \\
\text { Yüzey }\end{array}$ & $\begin{array}{l}\text { Tekniğe } \\
\text { Verilen Ad }\end{array}$ \\
\hline \multirow{2}{*}{$\begin{array}{l}\text { Fiziksel } \\
\text { Yöntemler }\end{array}$} & \multirow{2}{*}{ Düğümleme } & İplik & $\begin{array}{l}\text { Jaspe, } \\
\text { Salcaja }\end{array}$ \\
\cline { 2 - 4 } & Dikiş & Kumaş & $\begin{array}{l}\text { Adire } \\
\text { Onika }\end{array}$ \\
\cline { 2 - 4 } & Kumaş & $\begin{array}{l}\text { Adire } \\
\text { Alabere, } \\
\text { Adire } \\
\text { Alabera }\end{array}$ \\
\hline $\begin{array}{l}\text { Kimyasal } \\
\text { yöntemler }\end{array}$ & $\begin{array}{l}\text { Nişasta, pirinç } \\
\text { macunu (Stencil } \\
\text { yardımı ile) }\end{array}$ & Kumaş & $\begin{array}{l}\text { Adire eleko } \\
\text { (cassava } \\
\text { unu) }\end{array}$ \\
\hline
\end{tabular}


Tablo 9: Amerika'da Rezerve Boyama Tekniklerine Verilen İsimler

\begin{tabular}{|c|c|c|c|}
\hline $\begin{array}{l}\text { Rezerve } \\
\text { Yöntemi }\end{array}$ & Rezerve Tekniği & $\begin{array}{l}\text { Uygulandığı } \\
\text { Yüzey }\end{array}$ & $\begin{array}{l}\text { Tekniğe } \\
\text { Verilen Ad }\end{array}$ \\
\hline \multirow{3}{*}{$\begin{array}{l}\text { Fiziksel } \\
\text { Yöntemler }\end{array}$} & Düğümleme & $\begin{array}{l}\text { İplik, kumaş, } \\
\text { ürün }\end{array}$ & $\begin{array}{l}\text { Stretch dye } \\
\text { Knot dyeing }\end{array}$ \\
\hline & $\begin{array}{l}\text { Katlama } \\
\text { (klampsız) }\end{array}$ & $\begin{array}{l}\text { İplik, kumaş, } \\
\text { ürün }\end{array}$ & $\begin{array}{l}\text { Wrapped } \\
\text { resist }\end{array}$ \\
\hline & Dikiş & $\begin{array}{l}\text { İplik, kumaş, } \\
\text { ürün }\end{array}$ & Stitch-dyeing \\
\hline \multirow{2}{*}{$\begin{array}{l}\text { Mekanik } \\
\text { Yöntemler }\end{array}$} & $\begin{array}{l}\text { İp yardımı ile } \\
\text { rezerve }\end{array}$ & $\begin{array}{l}\text { İplik, kumaş, } \\
\text { ürün }\end{array}$ & Tie-dyeing \\
\hline & $\begin{array}{l}\text { Ahşap, şablon, } \\
\text { klamp yardımı } \\
\text { ile rezerve }\end{array}$ & $\begin{array}{l}\text { İplik, kumaş, } \\
\text { ürün }\end{array}$ & Clamp resist \\
\hline \multirow[b]{3}{*}{$\begin{array}{l}\text { Kimyasal } \\
\text { yöntemler }\end{array}$} & \multirow[t]{2}{*}{ Balmumu } & İplik & $\begin{array}{l}\text { İkat } \\
\text { Wax resist }\end{array}$ \\
\hline & & Kumaş, ürün & Batik \\
\hline & $\begin{array}{l}\text { Nişasta, } \\
\text { pirinç macunu } \\
\text { (Stencil yardımı } \\
\text { ile) }\end{array}$ & İplik & $\begin{array}{l}\text { Jam dyeing } \\
\text { Paste resist } \\
\text { Starch resist }\end{array}$ \\
\hline
\end{tabular}

Tablo 10: Pakistan'da Rezerve Boyama Tekniklerine Verilen İsimler

\begin{tabular}{|l|l|l|l|}
\hline $\begin{array}{l}\text { Rezerve } \\
\text { Yöntemi }\end{array}$ & $\begin{array}{l}\text { Rezerve } \\
\text { Tekniği }\end{array}$ & $\begin{array}{l}\text { Uygulandığı } \\
\text { Yüzey }\end{array}$ & $\begin{array}{l}\text { Tekniğe } \\
\text { Verilen Ad }\end{array}$ \\
\hline $\begin{array}{l}\text { Fiziksel } \\
\text { Yöntemler }\end{array}$ & Düğümleme & Kumaş & $\begin{array}{l}\text { Chunri } \\
\text { Chundri }\end{array}$ \\
\hline $\begin{array}{l}\text { Kimyasal } \\
\text { yöntemler }\end{array}$ & Çamur, kil & Kumaş & Ajrak \\
\hline
\end{tabular}

Tablo 11: Malezya ve Endonezya’da Rezerve Boyama Tekniklerine

\begin{tabular}{|c|c|c|c|}
\hline \multicolumn{4}{|c|}{ Verilen İsimler } \\
\hline $\begin{array}{l}\text { Rezerve } \\
\text { Yöntemi }\end{array}$ & $\begin{array}{l}\text { Rezerve } \\
\text { Tekniği }\end{array}$ & $\begin{array}{l}\text { Uygulandığı } \\
\text { Yüzey }\end{array}$ & $\begin{array}{l}\text { Malezya- } \\
\text { Endonezya }\end{array}$ \\
\hline \multirow{3}{*}{$\begin{array}{l}\text { Fiziksel } \\
\text { Yöntemler }\end{array}$} & \multirow{2}{*}{ Düğümleme } & İplik & Sumba \\
\hline & & Kumaş & $\begin{array}{l}\text { Plangi } \\
\text { Pelangi }\end{array}$ \\
\hline & Dikiş & Kumaş & Tritik \\
\hline $\begin{array}{l}\text { Kimyasal } \\
\text { yöntemler }\end{array}$ & Balmumu & Kumaş & $\begin{array}{l}\text { Parang } \\
\text { Vorstenlanden } \\
\text { batik } \\
\text { Pesisir } \\
\text { Coastal batik } \\
\text { Indramayu batik } \\
\text { Pekalongan batik }\end{array}$ \\
\hline
\end{tabular}

\subsection{Farklı Kültürlerde Fiziksel Rezerve Boya/Baskı Teknikleri}

Fiziksel rezerve boya/baskı teknikleri bağlama (düğümleme), klampsız katlama ve dikiş teknikleri gibi basit uygulamaları içermektedir. Bu teknikler ipliğe, kumaşa veya bitmiş ürüne uygulanabilmektedir.

Bağlama (düğümleme) rezerve tekniğine bakıldığında; ipliklerin bağlanması veya düğümlenmesi, ardından boyanması ile gerçekleşen rezerve tekniğinin Özbekistan, Hindistan, Japonya gibi ülkelerde çok eskilere dayanan bir teknik olduğu görülmektedir.

Bağlama rezerve tekniğinin en çok kullanılan örneği olarak ikat tekniğinin genellikle Hindistan'da geliştiği tahmin edilmektedir. Ajanta'daki duvar resimlerinde 7 yüzyıla ait olduğu tespit edilen çizgili ikat kumaşların desenleri, bu kumaşların Hint kültürünün etkileşimde olduğu günümüz Endonezya, Güney Doğu Asya, Yemen ve İpek Yolu boyunca yaygınlaştığını da göstermektedir (Crill, 1998, s. 16-18). Tekniğin farklı noktalarda bağımsız bir şekilde gelişmiş olabileceği de düşünülmektedir (Wang, 2005, s. 105-108).

Özbekistan'da Abr-bandi (Persler'deki abr kelimesinden gelmektedir) adı verilen bağlama rezerve tekniğinde pamuk-ipek iplikler kullanılarak, iplik cinsine uygun boyarmaddelerin kullanılması ile renklendirilen kumaşlara adras adı verilmektedir. Abrbandi (bağlı bulutlar) bir çözgü 
ikat tekniğidir ancak bölgede atlas kumaşlar daha fazla bilinmektedir. Dar anlamıla atlas, saten örgülü çözgü ikatını ifade eder ancak ikat sözcüğü ile dönüşümlü olarak tüm Orta Asya'daki ipek çözgü-ipek atkı ve ipek çözgü- pamuk atkı (adras) kombinasyonundan oluşan ikatları ve tüm örgü yapılarını da kapsamaktadır (Dusenbury, s. 2008). Abrbandi tekniği ile Bukhara, Margilan, Namangan, Kokand gibi şehirlerde dokunan kumaşlar Orta Asya'da parlak renkleri, çiçek, meyve, hayvan, ev gereçleri veya resimlerden oluşan motifleri ile bilinen iplik halinde boyanarak sonra dokunan kumaşlardır. Aynı teknik pamuk-ipek ipliklere uygulandığında abra veya adras, ipek kadife kumaş olarak uygulandığında ise baghmal adını almaktadır. Çizgili olarak üretilen bağlama rezerve kumaşlara ise bakasab denmektedir. Desenlere göre shoi, khan-atlas, atlas, podshokhi gibi isimler de almaktadır. Bu kumaşlar günümüzde sadece giysilerde değil kumaşlardan yapılan küpe, bileklik gibi aksesuarlarda da kullanılmakta ve özellikle düğün gibi özel günlerde hediye edilmektedir.

İpliklere uygulanan bağlama rezerve tekniği Hindistan'da ise ikat, patola veya mashru olarak adlandırılır. Mashru, Sanskritçe'de misru yani karışık anlamına gelmektedir ve çözgü yüzlü tekstil olarak bilinmektedirler. Patola ise çift katlı ipek ikatlara verilen isimdir (Gillow § Barnard, 1993, s. 94). İkatlar uygulanma yöntemlerine göre çeşitlenmektedir. İkatın en çok bilinen örneklerinden biri olan meng ikat Malay dilinde bind/ tie yani bağlama sözcüğünden türemiştir. Dokuma eyleminden önce ikat için iplikler tasarıma uygun bir şekilde renklendirilirler, ardından dokunarak kumaşa dönüşürler. İpliklere uygulanan rezerve işlemleri ardından üretilen kumaşlar, patola, chitka, telia rumal gibi isimler almaktadırlar (Gillow ve Barnard, 1993: 38). Kumaş ve bitmiş ürünlere uygulanan bağlama rezerve tekniği ise banda, bandhani, bandanna gibi isimlerle bilinmektedir ve bu şekilde üretilen ürünler, odhani, orni, chunari isimlerini almaktadır (Wada, 2012: 28). Kumaşın kendi etrafında, iplik yardımı ile sıkıca bağlanması ardından boyanması ise laheria adını almaktadır. Laheria Hintçe'de dalga anlamına gelmektedir.

İpliklere uygulanan bağlama rezerve tekniği, Japonya'da kasuri olarak bilinmektedir. Japonya'da, bing olarak bilinen çözgü ikat ise birinci sınıf geleneksel kumaşlar için yaygın bir boyama tekniğidir (Wang, 2005, s. 96).

İkat Çin'deki en eski boyama tekniğidir ve bu özel teknik günümüzde sadece Hainan'daki Li halkı arasında korunmaktadır. Diğer etnik gruplar da ikat tekniğine sahiptirler ancak bu gruplar genellikle kumaşları boyamadan önce dokurlar. Li halkı ise, kumaşları dokumadan önce, iplikleri rezerve edip boyayarak sadece desen katmanlarını zenginleştirmekle kalmaz, aynı zamanda yüksek sanat değeri gösteren bir bulanıklık etkisi de sunar. Panban cloth, Hainan Qingpan Sheet ve Hainan Checkboard Cloth adı verilen ikat kumaşlar, kraliyet haracı olarak anakaraya satılmıştır. İkat tekniği, günümüzde Çin'de çok nadir kullanılmaktadır. Bu zanaat Hainan'da bile sadece Changjiang Li Özerk Bölgesi ve Dongfang Li Meifu Bölgesi’nde görülebilmektedir. Günümüz Li halkında bu yeteneğe sahip en fazla on kadın vardır. Stretch dye Li'liler tarafından 'düğümlü boyama, boyama' (knot dyeing, dyeing) olarak adlandırılmaktadır. Bu şekilde üretilen kumaş eşsiz bir işçiliğe sahiptir. Belgeler, Song Hanedanlığı'ndan sonra kaydedilmiştir. Su Dongpo, Danzhou Dönemi'nde, Jun Ling Wan Miaoji (Changjiang Li bölgesinde yer alan Miao Özerk Bölgesi)'nde Li'nin stretch dyeing teknolojisine Hua Li adı verildiğini yazmıştır. Çözgüler puslu bir haldedir. Çözgüler atkı iplikleri ile dokunur, böylelikle brokar sanatının hassas bir parçasını oluşturur.

Örneğin, Santiago Atitlán'da giyilen perforalar, elli yıl boyunca sırt kemerli tezgâh (backstrap loom) (Acar, 2018) tezgâhta beyaz çizgili indigo pamuk kumaştan, sentetik indigo kumaşa, ardından basit renkler ile zenginleştirilmiş basit bir ikata, mor koyu mavi ve beyaz kullanılan basit ikat desenli sentetik kumaşlara kadar evrilmiştir (Stone, 2011: 485).

E-gasuri, Japonya'da rezerve boyamada ikat tekniği ile resimler oluşturma tekniğine verilen isimdir. Genel olarak ikat tekniğine Kasuri, resimli ikat tekniğine ise e-gasuri denmektedir. 'E' resim anlamına gelmektedir. Dokumadan önce ipliklere, bulanık dış hatlara sahip bir görüntü kazandırılır. Bu bulanık görünüm e-gasuri estetiğinin değerli bir yönüdür. E-gasuri genellikle (ancak geniş ölçekte değil) günümüz mavi beyaz renkli pamuklu ve sak lifli indigo boyama kumaşları ile ilişkilendirilmektedir. 1909 yılında, Shiraiishi Kai'nin keşfettiği hogushiori ise pirinç macunu ile rezerve edilen kumaşın stencil yardımı ile kasuriye benzer şekilde bulanık dış hatlara sahip görüntüler kazandırıldığı bir tekniktir. Ancak bu teknik geleneksel kasuri ve indigo boyamadan farklı olarak daha geniş bir renk paleti ile oluşturulmaktadır. Atkı ve çözgü iplikleri geçici gevşek iplikler ile tutularak boyama işlemi gerçekleştirilir. Bu şekilde üretilen pamuklu kumaşlar Niko-niko, ipek kumaşlar ise meisen adını almaktadır (Moeller, 
2008).

Bağlama boyama Amerika'da da bilinen bir rezerve boyama tekniğidir. Özellikle 1960 ve 70 ’lerde bu bağlama boyama tekniği ile renklendirilen parlak renkli tişörtler moda olmuştur (Hume, 2013).

Dikiş ile rezerve tekniğinde; boya alması istenmeyen bölümler belli bir düzene ya da desene göre dikilerek boyama yapılmaktadır. Endonezyaca bir terim olan tritik, bir desen oluşturmak üzere çeşitli şekillerde küçük hareketli dikiş sıraları ile yapılan bir rezerve tekniğidir. Dikiş ipliği çok sıkı bir şekilde çekildiğinde, kumaş toplanır ve sıkışır, böylece boyaya karşı bir direnç oluşturulur. Dikişler, düz veya zikzak sıralarla yapılabilir veya belirli bir şekle sahip olabilir. Dikişler kesilip kumaş açıldığında, boyalı bir arka plan ve dikişlerin olduğu kısımlarda küçük, boyanmamış noktalar görülür (Belfer, 1992, s. 7). Endonezya Java'da kain-kembegnan olarak adlandırılan kumaş, tritik tekniği ile desenlendirilmektedir. Bunun dışında, tritik tekniğini plangi tekniğinin bir çeşidi olarak tanımlayan kaynaklar da vardır (Hann, 2005: 31).

\subsection{Farklı Kültürlerde Mekanik Rezerve Boya/Baskı Teknikleri}

Mekanik Rezerve boya/baskı teknikleri tahta, klamp, ip gibi yardımcı malzemeler ile iplik, kumaş veya bitmiş ürünlerin bölgesel olarak kapatılması ile gerçekleşmektedir.

İp yardımı ile rezerve tekniğinde; iplik, kumaş veya ürünler rulo, kare, dikdörtgen gibi sert malzemeler üzerine sarılarak iplikler ile sıkıştırmakta ve rezerveye hazırlanmaktadır.

Ahşap, klamp gibi yardımcı malzemeler kullanılan rezerve tekniklerine bakıldığında farklı kültürlerde kumaş ve bitmiş ürünlere uygulanan yaygın bir teknik olduğu görülmektedir. Japon tekstil tarihi boyunca, kyokechi veya itajime shibori, katlanmış bir bez parçasının, kumaşın belirli alanlarını boyadan korumak için ahşap levhalar arasında sıkıştırılarak boyandığı bir desenlendirme işlemi olarak bilinmektedir. Itajime tekstil malzemeleri, karakteristik biçimde tekrar eden desenlere göre tanımlanmaktadır (Arai § Wada, 2010).

Beni ita, Beni itajime veya Kyo Beni gibi daha az bilinen itajime tekstil malzemeleri grubu çiçek, kuş gibi resimsel desenler ile oyulmuş tahtalar kullanılarak yapılan desenli, ince, hafif ipeklilerdir. Bu ipekliler Edo Dönemi (1603-1867) Meiji Dönemi (1868-1912) ve Erken Showa Dönemi'nde (192689) iç giysi, shitagi, kimono altı giysiler olarak kullanılmıştır ancak yaklaşık 100 yıl önce itajime kaybolmuştur (Arai §
Wada, 2010). Japonca'da 'itajime' kelime anlamı olarak 'levha sıkıştırma' anlamındaki ita (slab) ve kelepçe anlamındaki shimi veya jime birleşiminden meydana gelmektedir. Bu teknik kumaşın iki veya daha fazla yönde katlanması, pano ya da çubuklar arasına sıkıştırılması ile gerçekleşmektedir. En basit haliyle levhalar ve çubuklar düz kalmakta ve desen, boyanın açıktaki kat bezlerine nüfuz etmesi ile oluşmaktadır. Daha gelişmiş biçiminde, aynı desenlerle oyulmuş ince ahşap delikli tahta veya bloklar kullanılır, ancak ahşap blok baskısı ile aynı tarzda değildir. Pozitif görüntü, yükseltilmiş alanların kumaşın yüzeyine doğrudan aktarılan rengi alması ile oluşmaktadır. Bu teknik, katlanmış kumaşın oyulmuş iki pano ya da her bir levhadaki tasarımın birbirine tam olarak uyduğu bloklar arasına yerleştirildiği bir 'negatif' yöntem ile gerçekleşmektedir. Boyama işlemi sırasında çeşitli sıkıştırma teknikleri ile kumaşlara basınç uygulanmakta, böylece yükseltilmiş alanlara boyanın nüfuz etmesi engellenmiş olmaktadır. Boya alt katmanlara sızarak ayna görüntüsü ile desenleri oluşturulmaktadır (Wells, 2013).

Geleneksel Itajime ya da daha eski kyokechi tekniği, oyma tahtalar ya da bloklar kullanılarak oluşturulmuştur. Bu blokların boyutları değişse de Japonya'da devam eden üç yaygın form vardır; bunlar 27-47 cm uzunluğunda, $22 \mathrm{~cm}$ genişliğinde ve $1 \mathrm{~cm}$ kalınlığa sahip dikdörtgen plakalardır. $\mathrm{Bu}$ plakalar eğriliği olmayan ve ahşaptan boya girmesini önlemek amacı ile cilalanmış sert odundan yapılmaktadırlar. Bazılarının her iki tarafı da oyulurken, bazıları da tek tarafı oyuklu birer çift kalıp olarak oyulmaktadır. Bazı kalıplar ise oyulmadan kullanılmaktadır. Bunun amacı iki kalıp arasında karakteristik düz boyalı bir alan oluşturabilmektir. Diğer kalıplar ise kenarları oyulmuş kalıplardır, ya da ayrı kenar boyama kalıpları kullanılmaktadır (Wells, 2013). Rezervelerin kontrollü bir biçimde yapılabilmesi için kelepçeler kullanılarak şekil ve figürler oluşturulabilmektedir. Itajime veya jamdyeing olarak adlandırılan eski bir Japon tekniğinin bu adaptasyonunda, kesilmiş kontrplaklar, kalın plastikler veya bozuk paralar, katlanmış kumaşın her iki yanında eşit olarak sıralanmakta ve birbirine sıkıştırılmaktadır (Belfer, 1992, s. 7).

\subsection{Farklı Kültürlerde Kimyasal Rezerve Boya/Baskı Teknikleri}

Kimyasal rezerve boyamalarda ise iplik, kumaş veya bitmiş ürünler, bal mumu, nişasta, pirinç macunu, çamur, kil gibi malzemelerin yardımıyla renk gelişimlerinin engellenmesi ile 
yapılmaktadır. Bu malzemelerin uygulanması için tahta veya metal kalıplardan, çeşitli şablonlara ya da tijanting denilen metal küçük kepçelere kadar kültürlere göre farklılık gösteren çok çeşitli araçlar kullanılmaktadır.

Japonya'nın etkileyici tekstil geleneklerinde, birkaç yüzyıl boyunca pirinç unundan elde edilmiş macunla yapılan rezerve boya uygulamaları yeni tekniklerle gittikçe mükemmelleşmiştir. En tanıdık teknikler; bir koni veya tüp içine konan bir macun yardımı ile serbest el çizimleri ile rezerve katmanı oluşturulan tsugugami tekniği ve ince kesilmiş kağıt şablonlar ile uygulanan katazome tekniğidir (Belfer, 1992, s. 6). Katazome'nin 16. yüzyılda Heian Dönemi'nde ortaya çıktığı düşünülmektedir. Kelime kökü olarak bakıldığında kata; stencil/pattern, zome ise dye sözcüklerinin bir araya gelmesi ile oluşmuştur ve macun ile rezerve boyama anlamına gelmektedir. Kullanılan renklere göre farklı isimler alabilen katazomelerin, gelenekselleşmiş en önemlilerinden biri kırmızı boya ile yapılan bingatazomedir (Murashima, 1993, s. 11). Bir tüpün içine koyulan rezerve macunu ile resim gibi çizilerek hazırlanan kumaşlar ise tsutsugakizome adını almaktadır. İronori adı verilen kendinden renkli bir macun ile boyanan kumaşlar ise nazome olarak adlandırılmaktadır (Murashima, 1993, s. 15). Tüm bu teknikler zaman içerisinde birbirleri ile karıştırılarak da kullanılmıştır. Bu tür tekniklerin en önemlileri katazome ve tsutsugaki birlikteliğinde oluşan shiborizome, katazome, tsutsugaki, shibori ve nakış ile oluşan tsujigana ve farklı stencillerin birleşimi il oluşan oborogata'dır (Murashima, 1993, s. 15-79).

Çin'de ise macun ile rezerve boyama tekniği, diğer rezerve boyama tekniklerinden daha sonra kullanılmaya başlanmıştır. Bu teknik, balmumu rezerve ve klamp ile rezerve tekniklerinin birleşiminden oluşmaktadır. Tang Hanedanlığı döneminde, sınırlı olan balmumu ihtiyaçları karşılayamadığı için, boyama ustaları alternatif bir rezerve malzemesi arayışına girmişlerdir. 0 dönemde nişasta kullanılmakta ancak çözünürlüğü nedeni ile iyi sonuç vermemektedir. Araştırmalar sonucunda, bitki külleri ve yanmış istiridye kabuklarından oluşan yapışkan bir rezerve macunu elde edilmiştir. Bir sonraki işlem, farklı desenlerde kesilmiş ahşap şablonlar veya farklı desenlerde oyulmuş kalıplar kullanılarak ipek kumaşın macun ile rezerve edilmesidir. Rezerve edilen kumaş boyandıktan sonra kumaşın boyanan kısımlarının kapatılması ile ikinci bir renklendirme işlemi yapılmaktadır. Bu şekilde üretilen ipekli kumaşlar huixie (kül ile rezerve edilen desenli kumaş) adını almaktadır.
Balmumu eksikliği karşısında geliştirilen bu yöntemin yakın bir zaman sonra bir dezavantajının olduğu fark edilmiştir. Rezerve malzemesinin içerisine konan külün yüksek alkali içeriği, ipeğin hassas yüzey yapısına zarar vermektedir. Bu nedenle başka teknik arayışları içerisine girilmiş, deneme yanılmalar sonucunda soya fasulyesi unu, sönmüş kireçten oluşan uygun bir rezerve malzemesi elde edilmiştir. Zamanla da kesilmesi kolay olan kâğıt şablonlar, ahşap olanların yerini almıştır (Tsang, 2005: 39).

Çeşitli nişasta ve zamklar, balmumuna alternatif olarak kullanılmıştır. Basit bir un ve arap zamkı macunu blok baskı ve serigrafi tekniklerinde oldukça başarılı performans sergilemektedir. Daha yapışkan olan cassava unu ise geleneksel el boyama ve stencil baskılı kumaşlarda daha fazla kullanılmıştır. Çünkü blok baskı veya serigrafi için fazla yapışkandır. Japonların kullandığı pirinç macunu ise ince bir tahta spatula veya bir tüp yardımı ile çekilerek stencil baskıda kullanılabilmektedir (Hann, 2005, s. 20). Kesilen şablonlar yağlı manila kartı veya plastik gibi sert olmalıdır. Macunlar sert boya fırçaları, kart parçaları veya ince tahtalar kullanılarak uygulanabilmektedir. Kumaş yüzeyinde kırık bir desen oluşturulmak isteniyorsa, sıcak olarak kullanılan dekstrin malzemesi ile blok baskı veya serigrafide pek çok kumaş çeşidi üzerinde başarılı bir sonuç alınmaktadır. Ancak, boyama işlemi tamamlandıktan sonra kumaşı sıcak sabunlu suda kaynatarak nişasta izlerini gidermek gerekmektedir (Hann, 2005, s. 21).

Batik, Avrupa'da modern zanaatkârlar arasında da oldukça yaygındır. Balmumu en çok kullanılan rezerve malzemesidir. Çeşitli uygulamaları yapılmakta ancak ince çizgilere ulaşmak için Cava tarzı bir canting kullanılmaktadır. Balmumu ile çalışılırken balmumu sabit $80^{\circ} \mathrm{C}$ 'de tutularak eriyik halde iken çalışılmalıdır. Balmumu çok sıcak olduğunda hızlı bir şekilde kumaş üzerinde yayılarak kontrol edilememekte, çok soğuk olduğunda ise çok çabuk kuruduğu için düzgün bir rezerve yapılamamaktadır. Tek renkli bir tasarım, balmumu ile rezerveden hemen sonra boyanabilmektedir. Çok renkli bir tasarım ise her renk katmanı için birden fazla kapatma ve boyama işlemi gerektirmektedir. Boyamanın soğuk yapılması önemlidir, özellikle pamuk ve ipekli kumaşların boyanmasında soğuk su-reaktif boya uygundur. Boyama esnasında kumaşı mümkün olduğunda düz tutmak önemlidir, aksi takdirde balmumu çatlayarak boyanın penetrasyonuna izin verebilmektedir. Her bir boyama aşamasından sonra 
balmumu kumaştan iyice temizlenmelidir. Bu da kumaşın sıcak suda kaynatılması ya da kâğıt katmanları arasında ütülenmesi ile yapılabilmektedir (Hann, 2005, s. 21). Batik yapımının bazı teknikleri, yaklaşık 100 yıl önce Java'da tjap veya bakır el pulu kullanımıyla değişmiştir (Belfer, 1992, s. 14). Balmumu rezerve tekniği Çin'de ortaya çıkmamıştır. Xie'nin asıl kullanımı, bağlama boyamadır (Gaspa, Michel ve Nosch, 2017, s. 447, 448).

Nijerya'da, adire eleko terimi, şablonlar ile uygulanan cassava unu ile hazırlanan, indigo boyalı dekoratif kumaşlara atıfta bulunmaktadır. Diğer varyasyonlar, macunu kumaşın tüm yüzeyine düzgün bir şekilde uygulamanın ardından bir tarak veya benzeri bir aletle kazıma yoluyla tasarım oluşturmayı içermektedir (Belfer, 1992, s. 6).

Japonya'da bal mumu ile yapılan rezerve tekniği rokechi olarak bilinmektedir. Rokechi'de, kumaş boyamadan önce mum ile rezerve edilmekte ve boyama sonrası mum uzaklaştırılmaktadır. Katazome'de mum benzeri bir macun kullanılır, ancak rokechiden farklı olarak katazomede macun bir stencil yardımı ile uygulanmaktadır. Katazome tekstil malzemelerini, daldırma boyama ile renklendirilmektedir. Yuzen tekniğinde ise şablon kullanılarak ya da koni şeklinde bir boru ile rezerve uygulanmakta ve daldırma boyama yerine küçük fırça uygulaması ile renklendirme yapılmaktadır. (Wada, Rice, \& Barton, 1999).

\section{Sonuç}

Rezerve teknikleri farklı kültürlerde farklı malzeme ve araçlarla uygulamalarının yanı sıra çeşitli dillerden kaynaklanan oldukça zengin kavram ve terimler dağarcığı oluşturmuştur. Coğrafyaya bağlı olanaklar çerçevesinde her kültür belli teknikleri daha severek uzmanlaşmış ve ürettikleri ile tekstil tarihine önemli katkılar yapmıştır.

Rezerve teknikleri alanında gerek teorik araştırma gerekse uygulama yapacakların bu kavram ve terimleri bilmesi önemlidir. Yeni tekniklerin geliştirilmesinde geleneksel uygulamaların avantaj ve dezavantajlarının gözden geçirilmesinde yarar bulunmaktadır.

Genelden özele doğru bunların fiziksel, mekanik ya da kimyasal rezerve tekniği mi olduğunun bilinmesi ve ardından çalışılmak istenen tekniğin farklı kültürlerdeki karşılığının ve uygulama biçimlerinin öğrenilmesinin bir rehber niteliği taşıyabileceği düşünülmektedir.
Yapılan çalışmada kullanılan bölgeye özgü terimler derlenmeye çalışılmış olmakla birlikte yöreye özgü bir teknik uygulanıp özel bir ad verilmedikçe tüm rezerve uygulamaları genel olarak bağlama/boyama (tie/dye), batik vb. yaygın olarak kullanılan isimlerle anılmaktadır.

Devam eden geleneksel teknikler kendine özgü adlarla yaşarken, rezerve tekniklerinin çağdaş yorumlarından dolayı günümüzde uygulanan teknikler ortak adlandırma eğilimi göstermektedir. Bu eğilim de temel olarak mekanik ve fiziksel rezerve tekniğini bir ele alarak bağlama/boyama (tie/dye), kimyasal rezerve tekniğinin en yaygın uygulaması olarak mumla rezerveyi (wax resist) batik olarak adlandırma eğilimi göstermektedir.

\section{Kaynakça}

Acar, S. (2018). Tekstil Tarihi Ders Notu, Dokuz Eylül Üniversitesi Güzel Sanatlar Fakültesi, İzmir.

Arai, M. § Wada, Y. (2010). "Beni itajime: carved board clamp resist dyeing in red" Textile Society of America Symposium

Belfer, N. (1992). Batik and Tie Dye Techniques. New York: Dover Publication Inc.

Crill, R. (1998). Indian Ikat Textiles. L.: Victoria and Albert Publications, 1998.

Dusenbury, M. M. (2008). “atlas today: patterns of production, bazaars and bloomingdales Uzbekistan and Xinjiang, China”, Textile Society of America Symposium Proceedings

Erdem İşmal, Ö. § Yıldırım, L. (2012). Tekstil Baskıcılığının Tarihçesi. İzmir : Dokuz Eylül Üniversitesi Yayınları, Güzel Sanatlar Fakültesi Yayın No:1.

Foulds, J. (1995). Dyeing and Printing: A Handbook. Intermediate Technology Publications.

Gaspa, S., Michel, C. § Nosch, M.-L. (2017). Textile Terminologies from the Orient to the Mediterranean and Europe, 1000 BC to 1000 AD, Lincoln: Zea Books.

Gillow, J. § Barnard, N. (1993). Traditional Indian Textiles, Thames \& Hudson Ltd; Reprint edition.

Hann, M. A. (2005). Patterns of Culture Techniques of Decoration and Coloration. Leeds: The University of Leeds International Textiles Archive.

Hume, S. (2013). University of Kent State. https://www.kent. edu/museum/resist-world-resist-dye-techniques 
$(13.12 .2017)$

Moeller, A.M. (2008). "Prosperity, longevity, and "happily ever-after": symbolism and the sophistication of implication in japanese e-gasuri(picture ikat) textiles", Textile Society of America Symposium Proceedings

Murashima, K. (1993). Katazome, Usborne: Lark Books.

Stone, C. (2011). The Philippines and Guatemala: a Tale of Three Textiles, Kunstkamera Büyük Peter Antropoloji ve Etnografya Müzesi Elektronik Kütüphanesi, 470490.

Tang, J. (2017). “Comparison of patterns in japanese ıkat and chinese li ıkat” Boletín Técnico, Vol.55, Issue 13, 244-250.

Teker, M. S. (2015). “Kapatma Maddesi ile Rezerve Boyama Teknikleri”, Akademik Sosyal Araştırmalar Dergisi, Yıl: 3, Sayı: 18, Aralık2015, 478 -493.

Thompson, R. (2014). Manufacturing Processes For Textile And Fashion Design Professionals. London: Thames \& Hudson.

Tsang, K. B. (2005). Touched by Indigo. Canada: Royal Ontario Museum http://eacharya.inflibnet.ac.in/dataserver/eacharya-documents /53e0c6cbe413016f2344 36ed INFIEP_8/85/ET/ unit-4\%20Lesson\%2010.pdf (24.01.2018)

Wada, Y. I. (2012). Memory on Cloth: Shibori Now, New York: Kodansha International.

Wang, H. (2005). “Exploratory study of the origin of the ancient 1 kat dyeing technique and its spread in china”, Journal of the Textile Institute, 105-108.

Wells, K. (1997). Fabric Dyeing \& Printing. London: Conran Octupus Ltd.

Wells, K. (2013). “Invent-reinvent itajime’ digital created board clamping”, The 2nd International Textiles and Costume Congress 